\title{
BESOV-MORREY SPACES AND VOLTERRA INTEGRAL OPERATOR
}

\author{
RONG YANG AND XIANGLING ZHU*
}

Abstract. In this paper, we introduce a class of Besov-Morrey spaces $B_{p}^{\lambda}(s)$. For any positive Borel measure $\mu$, we characterize the boundedness and compactness of the identity operator from $B_{p}^{\lambda}(s)$ spaces into tent spaces $T_{t}^{q}(\mu)$. As an application, the boundedness, compactness and essential norm of the Volterra integral operator $T_{g}$ from $B_{p}^{\lambda}(s)$ spaces to some general function spaces are also investigated.

Mathematics subject classification (2020): 30H25, 47B38.

Keywords and phrases: Besov-Morrey space, Carleson measure, Volterra integral operator.

\section{REFERENCES}

[1] A. Aleman and A. Siskakis, An integral operator on $H^{p}$, Complex Var. Theory Appl. 28 (1995), $149-158$.

[2] A. Aleman AND A. SiskaKis, Integration operators on Bergman spaces, Indiana Univ. Math. J. 46 (1997), 337-356.

[3] D. Blasi And J. PAU, A characterization of Besov type spaces and applications to Hankel type operators, Michigan Math. J. 56 (2008), 401-417.

[4] P. Galanopoulos, N. Merchán and A. Siskakis, a family of Dirichlet-Morrey spaces, Complex Var. Elliptic Equ. 64 (2019), 1686-1702.

[5] P. Galindo, M. Lindström And S. Stević, Essential norm of operators into weighted-type spaces on the unit ball, Abstr. Appl. Anal. Vol. 2011, Article ID 939873, (2011), 13 pages.

[6] D. Girela And J. Peláez, Carleson measure, multipliers and integration operators for spaces of Dirichlet type, J. Funct. Anal. 241 (2006), 334-358.

[7] B. HU AND S. LI, $N(p, q, s)$-type spaces in the unit ball of $\mathbb{C}^{n}(V)$ : Riemann-Stieltjes operators and multipliers, Bull. Sci. Math. 166 (2021), 102929, 27 pp.

[8] L. Hu, R. YAng AND S. Li, Dirichlet-Morrey type spaces and Volterra integral operators, J. Nonlinear Var. Anal. 5 (2021), 477-491.

[9] P. LI, J. LiU AND Z. LoU, Integral operators on analytic Morrey spaces, Sci. China Math. 57 (2014), 1961-1974.

[10] S. Li, J. LiU And C. Yuan, Embedding theorem for Dirichlet type spaces, Canad. Math. Bull. 63 (2020), 106-117.

[11] S. Li AND S. STEVIĆ, Generalized weighted composition operators from $\alpha$-Bloch spaces into weighted-type spaces, J. Inequal. Appl. Vol. 2015, Article No. 265, (2015), 12 pages.

[12] Q. Lin, J. LiU AND Y. WU, Volterra type operators on $S^{p}(\mathbb{D})$ spaces, J. Math. Anal. Appl. 461 (2018), 1100-1114.

[13] X. LiU, S. Li AND R. Qian, Volterra integral operators and Carleson embedding on Campanato spaces, J. Nonlinear Var. Anal. 5 (2021), 141-153.

[14] J. LiU AND Z. Lou, Carleson measure for analytic Morrey spaces, Nonlinear Anal. 125 (2015), 423-432.

[15] J. LiU, Z. LOU AND C. XIONG, Essential norms of integral operators on spaces of analytic functions, Nonlin. Anal. 75 (2012), 5145-5156.

[16] J. PAU AND R. ZhaO, Carleson measures, Riemann-Stieltjes and multiplication operators on a general family of function spaces, Integral Equations Operator Theory 78 (2014), 483-514. 
[17] C. Pommerenke, Schlichte Funktionen und analytische Funktionen von beschränkter mittlerer Oszillation, Comment. Math. Helv. 52 (1997), 591-602.

[18] R. QIAN AND S. Li, Volterra type operators on Morrey type spaces, Math. Inequal. Appl. 18 (2015), 1589-1599.

[19] R. QIAN AND S. LI, Carleson measure and Volterra type operators on weighted BMOA spaces, Georgian Math. J. 27 (2020), 413-424.

[20] R. QIAN AND X. ZHU, Embedding of $Q_{p}$ spaces into tent spaces and Volterra integral operator, AIMS Math. 6 (1) (2020), 698-711.

[21] C. SHEN, Z, LOU AND S. LI, Embedding of BMOA $A_{\log }$ into tent spaces and Volterra integral operators, Comput. Methods Funct. Theory. (2020), 1-18.

[22] C. Shen, Z. Lou And S. LI, Volterra integral operators from $D_{p-2+s}^{p}$ into $F(p \lambda, p \lambda+s \lambda-2, q)$, Math. Inequal. Appl. 23 (2020), 1087-1103.

[23] B. SEHBA AND S. STEvić, On some product-type operators from Hardy-Orlicz and Bergman-Orlicz. spaces to weighted-type spaces, Appl. Math. Comput. 233 (2014), 565-581.

[24] Y. SHI AND S. Li, Essential norm of integral operators on Morrey type spaces, Math. Inequal. Appl. 19 (2016), 385-393.

[25] A. Siskakis AND R. ZHaO, A Volterra type operator on spaces of analytic functions, Contemp. Math. 232 (1999), 299-312.

[26] S. STEVIĆ, On a new integral-type operator from the Bloch space to Bloch-type spaces on the unit ball, J. Math. Anal. Appl. 354 (2009), 426-434.

[27] S. STEVić, Norm and essential norm of an integral-type operator from the Dirichlet space to the Bloch-type space on the unit ball, Abstr. Appl. Anal. Vol. 2010, Article ID 134969, (2010), 9 pages.

[28] S. STEVIĆ, Essential norm of some extensions of the generalized composition operators between $k$ th weighted-type spaces, J. Inequal. Appl. Vol. 2017, Article No. 220, (2017), 13 pages.

[29] S. STEVIĆ AND Z. JIANG, Boundedness and essential norm of an integral-type operator on a HilbertBergman-type spaces, J. Inequal. Appl. Vol. 2019, Article No. 121, (2019), 27 pages.

[30] S. STEVIĆ, A. SHARMA AND A. BHAT, Essential norm of products of multiplication composition and differentiation operators on weighted Bergman spaces, Appl. Math. Comput. 218 (2011), 2386-2397.

[31] S. Stević, A. Sharma And A. Bhat, Products of multiplication composition and differentiation operators on weighted Bergman spaces, Appl. Math. Comput. 217 (2011), 8115-8125.

[32] M. TJanI, Compact composition operators on some Möbius invariant Banach spaces, Michigan State University, Department of Mathematics (1996).

[33] Z. Wu AND C. XIE, Q spaces and Morrey spaces, J. Funct. Anal. 201 (2003), 282-297.

[34] R. ZHaO, On a general family of function spaces, Ann. Acad. Sci. Fenn. Math. Diss. 105 (1996), 56.

[35] J. ZHOU AND X. ZHU, Essential norm of a Volterra-type integral operator from Hardy spaces to some analytic function spaces, J. Integral Equations Appl. 28 (2016), 581-593.

[36] K. ZHU, Operator theory in function spaces, 2nd edn, American Mathematical Society, Providence (2007). 